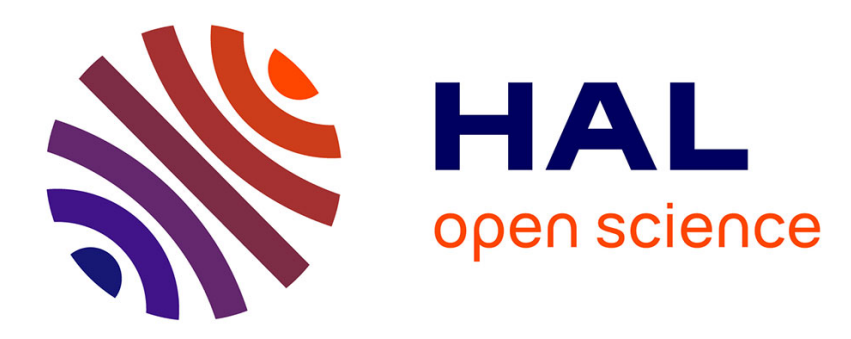

\title{
Further evidence for infants' preference for prosocial over antisocial behaviors
}

Céline Scola, Claire Holvoet, Thomas Arciszewski, Delphine Picard

\section{To cite this version:}

Céline Scola, Claire Holvoet, Thomas Arciszewski, Delphine Picard. Further evidence for infants' preference for prosocial over antisocial behaviors. Infancy, 2015. hal-01793532

\section{HAL Id: hal-01793532 \\ https://hal.science/hal-01793532}

Submitted on 16 May 2018

HAL is a multi-disciplinary open access archive for the deposit and dissemination of scientific research documents, whether they are published or not. The documents may come from teaching and research institutions in France or abroad, or from public or private research centers.
L'archive ouverte pluridisciplinaire HAL, est destinée au dépôt et à la diffusion de documents scientifiques de niveau recherche, publiés ou non, émanant des établissements d'enseignement et de recherche français ou étrangers, des laboratoires publics ou privés. 


\section{Further evidence for infants' preference for prosocial over antisocial behaviors}

Celine Scola*, Claire Holvoet, Thomas Arciszewski, \& Delphine Picard Aix Marseille Univ, PSYCLE EA3273, 13621 Aix en Provence, France

* Corresponding author: celine.scola@univ-amu.fr

Abstract

This study extends the findings that young infants prefer prosocial to antisocial others (Hamlin, Wynn, \& Bloom, 2007; Hamlin \& Wynn, 2011) to older infants (12-to-24 months, and 24-to-36 months) with a novel display. We presented infants with short cartoons in which a character (the « Protoganist ») engaged in a ball play with two others, one acting prosocially (the « Giver »), and the other antisocially (the « Keeper »). Afterwards, infants were presented with the Giver and the Keeper characters and encouraged to reach for the one of their choice. We found that infants exhibited robust choice for the Giver. In addition, infants' preference for the Giver persisted despite changes in facial features (dark skin, scrambled face). These findings provide further evidence for infant's preference for prosociality.

Keywords: Infancy, social cognition, prosocial, moral, preference

Acknowledgments

We thank Vitrolles's town council for it support, the staff of the nurseries for their very nice welcome, and the parents and infants for their kind participation. Thanks to Nina Taurel for her help in data collection. 
Introduction

The ability to evaluate others is fundamental to the perception of the social world. Assessing others' intentions and motives is crucial for choosing appropriate social partners and avoiding inappropriate or even dangerous ones. Previous studies (Hamlin, Wynn, \& Bloom, 2007, 2010; Hamlin \& Wynn, 2011; for a review see Hamlin, 2013) have shown that during their first year of life infants have skills to evaluate the social world around them. Using the "climbing the hill" paradigm, Hamlin et al. (2007) presented infants aged 6 and 10 months with a wooden block (with glued eyes) struggling to climb a hill who was either pushed from behind by a helper (prosocial character) or pushed down by a hinderer (antisocial character). When infants were presented with both characters, then they robustly chose the helper. Measuring preferential looking, Hamlin et al. (2010) showed that 3-months-old infants also demonstrated preference for the prosocial character in the "climbing the hill" paradigm. In 2011, Hamlin and Wynn replicated and extended their initial findings to 3-, 5-, and 9months-old infants, using two novel paradigms: "opening a box to get a toy" (where an animal puppet struggling to open a box was either helped or hindered achieving his goal) and "retrieving a dropped ball" (where an animal puppet having accidentally dropped his ball was either helped or hindered achieving his goal). Regardless of age, infants exhibited a preference for the prosocial character. Altogether these findings supported the view that very early infants engaged in social evaluation, and exhibited preference for prosocial over antisocial others.

To our knowledge, three studies have attempted to replicate the findings by Hamlin and colleagues. One study has used the "climbing the hill" paradigm (with slight methodological changes) with 10-months-old infants (Scarf, Imuta, Colombo, \& Hayne, 2012), and has provided a non-social interpretation of infant's preference for the prosocial character (see for a reply: Hamlin, 2015). The other two have used the "opening a box to get a 
toy" paradigm with 8-months-old infants (Salvadori, et al., 2015) and 43-months-old toddlers (Maxwell \& Raftseder, 2015), and have failed to report a significant preference of infants for the prosocial character over the antisocial one. This is surprising and calls for conducting additional replication attempts, together with an investigation of the conditions under which infants' preference for prosocial behavior is evidenced (or not).

We designed the present study from a twofold perspective. First, we tested whether the prominent finding that young infants prefer prosocial to antisocial others (cf. Hamlin) would extend to older infants (i.e., infants after their first year of life) and with a novel display (cartoons). Unlike previous studies, we observed infants aged 12-to-24 months and 24-to-36 months, because we lacked data on infants' social evaluation after their first year of life. Importantly, unlike previous studies, we built and used cartoons involving human-like characters, so as to permit better control over the sequence of events that were presented to infants. We believe that one drawback with manipulating on-line animal puppets to mimic social interactions is that the way a scenario was played and timed was likely to vary across trials. By contrast, cartoons offered full control over the sequence of events, ensuring a strictly constant timing across repeated trials. In addition, we used human-like characters (rather than wooden blocks or animal puppets) to increase the ecological validity of the social scenario.

Second, to assess the robustness of infants' preference for prosociality, we tested whether infants' preference for a prosocial agent would persist despite featural changes made in the stimuli. Indeed, when evaluating others, infants might also pay attention to facial features, and not solely to overt behaviors. Several studies have shown that young infants preferred own-race versus other-race faces (Kelly et al., 2007), as well as normal versus scrambled faces (Fantz, 1961). In the present study, we set up additional conditions in which the prosocial character either had dark skin or a scrambled face. 
To summarize, this study addressed two research questions: i) Would infants aged 12to-24 months and 24-to-36 months demonstrate preference for prosocial behavior when presented with cartoons involving human-like characters? ii) Would preference for prosocial behavior still hold when the prosocial character had dark skin or a scrambled face? Based on Hamlin's findings, we predicted that infants would demonstrate preference for the prosocial character, and would prioritize prosociality above all else (namely, above featural changes).

Method

\section{Participants}

Thirty-nine full-term infants participated in the study. They were divided in the following two age groups: 12-to-24-months $(n=14$; age range $=13$ to 23 months, Mean age $=19$ months, $\mathrm{SD}=3$ months; 6 boys and 8 girls $)$, and 24-to-36-months $(n=25$; age range $=$ 26 to 36 months, Mean age $=32$ months, $\mathrm{SD}=3$ months; 14 boys, and 11 girls). Eleven additional infants took part in the study (four infants in the 12-to-24-months age group, and seven infants in the 24-to-36-months age group), but were excluded from the analyses because they failed to choose either character during the test phase. All infants were full-term and healthy. They were Caucasian and came from middle to upper class families in a southern French city. Written consent was obtained from the parents of the infants. The study was carried out in accordance with the latest Declaration of Helsinki.

\section{Material}

We built color cartoons with Adode Flash ${ }^{\mathrm{TM}}$, in which three infant-like characters (either boys or girls, depending on the infant's gender) interacted during a ball game on a simple background. The central character (the "Protagonist") played with a ball, and then threw the ball alternatively to each character to play with them. One character gave the ball 
back to continue playing (the "Giver", or prosocial character), whereas the other character kept the ball and left the playground (the "Keeper", or antisocial character).

There were five different cartoons: three were used in the experimental conditions (A, B, and C, which are illustrated in Fig. 1.), and two were used in the control conditions (B', and C'). In condition A (prosociality baseline condition), the Giver and the Keeper had white skin and normal facial features. In condition B (skin color condition), the Giver had dark skin whereas the Keeper had white skin; both had normal facial features. In condition C (scrambled face condition), the Giver had a scrambled face whereas the Keeper had a normal face; both had white skin. The control conditions B' and C' were similar the experimental condition B and C, respectively, except that both characters had a prosocial behavior. The duration of each cartoon was 10 seconds.

(Insert Fig. 1. about here)

\section{Procedure}

The session was individual, and took place in a small room in a French kindergarten. Infants sat on a chair on the laps of a kindergartner with whom they were familiar. Infants were facing a laptop where cartoons were displayed. In order to ensure that kindergarteners will not influence infants, they were instructed to keep a neutral posture, and to not talk or interact with the infants during the whole session. A female experimenter explained infants that they were going to see cartoons, using the following verbal instruction: « Hi, I will show you some cartoons on this screen, in which three characters are playing a ball game. At the end of the cartoon, I will show you two of these characters, and you would have to choose the one you prefer. Are you OK with this? So here we go! ». At the end of each cartoon, a second female experimenter immediately presented infants with the Giver and the Keeper (cut in flat cardboard shapes) and asked them to indicate the one they preferred. Following the choice test procedure used by Hamlin et al. (2007), preference for a character was evidenced when 
infants attempted to reach the character while simultaneously looking at him. The two female experimenters performed the coding of infants' responses (100\% agreement).

Infants were presented successively with all five cartoons, in a randomized order for each infant. For experimental conditions (A, B, and C), spatial position of Giver (left or right) with respect to the infant was counterbalanced in the cartoons and at choice test across infants in each age group. For condition A, we also counterbalanced color of the Giver's T-shirt (orange or green) across infants in each age group. For conditions $\mathrm{B}$ and $\mathrm{C}$, and the control conditions, color of the shirts was kept constant (green), as both characters had different faces. For control conditions (B', and C'), we counterbalanced the spatial position of the two characters (white versus dark skin; scrambled versus normal face) with respect to the infant (left or right) in the cartoons and at choice test across infants in each age group.

Results

Fig. 2. shows the percentage of infants who chose the Giver and the Keeper in each experimental condition. In line with our predictions, the results in Fig. 2. showed that infants in the prosociality baseline condition tended to prefer the Giver, and this preference appeared to persist in the skin color condition and scrambled face condition.

(Insert Fig. 2. about here)

In the prosociality baseline condition (see Fig.2.), binomial tests indicated that infants preferred significantly the Giver over the Keeper character (30 of 39 infants chose the Giver, one-tailed $p<.01$ ). Preference for the Giver was observed at age 12-to-24-months (12 of 14 infants, one-tailed $p<.01$ ), as well as at age 24-to-36-months (18 of 25 infants, one-tailed $p<$ .05). There was no significant difference in preference distribution across the two age groups (Fisher exact probability test, $p=.44$ ). There was no effect of order, color of T-shirt, or side of character on any of the comparisons. 
In the skin color condition (see Fig.2.), binomial tests indicated that infants preferred significantly the Giver over the Keeper character (26 of 39 infants chose the Giver, one-tailed $p<.05)$. When the analysis was run for each age group separately, preference for the Giver was not significant at age 12-to-24-months ( 9 of 14 infants, one-tailed $p=.21$ ), whereas it was at significance level at age 24 -to-36-months (17 of 25 infants, one-tailed $p=.05$ ). There was however no significant difference in preference distribution across the two age groups (Fisher exact probability test, $p=.99$ ), which suggested that the lack of statistically significant preference observed in the young age group, but not in the older one, was a power issue. Comparison between infants' choices in the prosociality and skin color conditions indicated that preferences did not change significantly across conditions (McNemar tests for change, two-tailed, $p=.45 ; 12-24$ months: $p=.45 ; 24-36$ months: $p=.99)$. Findings from the skin color condition were unlikely biased by spontaneous preferences of infants toward characters with dark versus white skin: in the control condition B', infants exhibited no preference for either character (19 of 39 infants chose the character with a white skin, binomial test, onetailed $p=.50)$. Among these 19 infants, 13 shifted to a black skin preference in the skin color condition, while six maintained a white skin preference (binomial test, one-tailed, $p=.08$ ).

In the scrambled face condition (see Fig.2.), binomial tests indicated that infants preferred significantly the Giver over the Keeper character (27 of 39 infants chose the Giver, $p<.05)$. When the analysis was run for each age group separately, preference for the Giver was not significant at age 12-to-24-months ( 9 of 14 infants chose the giver, $p=.21$ ), whereas it was significant at age 24-to-36-months (18 of 25 infants chose the Giver, $p<.05$ ). Again, there was no significant difference in preference distribution across the two age groups (Fisher exact probability test, $p=.72$ ). Comparison between infants' choices in the prosociality and scrambled face conditions indicated that preferences did not change significantly across conditions (McNemar tests for change, two-tailed, $p=.58 ; 12-24$ months: 
$p=.25 ; 24-36$ months: $p=.99)$. Also, comparison between infants' choices in the skin color and scrambled face conditions indicated that preferences did not change significantly across conditions (McNemar tests for change, two-tailed, $p=.99 ; 12-24$ months: $p=.99 ; 24-36$ months: $p=.99)$. Findings from the scrambled face condition were unlikely biased by spontaneous preferences of infants toward characters with scrambled versus normal faces: in the control condition C', infants exhibited no preference for either character (18 of 39 infants chose the character with a normal face, binomial test, one-tailed $p=.37)$. Among these 18 infants, 13 shifted to a scrambled face preference in the scrambled face condition, while five maintained a normal face preference (binomial test, one-tailed, $p<.05$ ).

\section{Discussion}

This study extends the prominent finding that young infants prefer prosocial to antisocial others (cf. Hamlin) to older infants (after their first year of life) and with a novel display (cartoons). Our findings indeed indicated that 12-to-24 and 24-to-36-months old infants demonstrated a significant preference for the Giver (over the Keeper) in a play a ball scenario. Whereas previous studies have failed to replicate Hamlin's results (e.g., Salvadori et al., 2015), our study is the first to provide further evidence for infants' preference for prosocial over antisocial behaviors, using reaching behavior as a measure of preference.

Our study additionally revealed that infants' preference for the prosocial character was maintained despite changes in the facial features of the prosocial agent (namely, a dark skin or a scrambled face). This finding is new and provides support for the robustness of infants' responses to prosociality. An alternative interpretation of our findings would be that infants actually responded to the antisocial nature of the Keeper, who was the same across all conditions, without much considering changes in skin color or face configuration of the prosocial character. Additionally, it may even be the case that infants saw the Giver as 
prosocial without noticing the face at all, given that all of the other available cues (body, animate action, etc.) were sufficient to support a social interpretation and evaluation. Future studies using eye-tracking technology would be helpful in this regard.

To conclude, the present study adds substantial support for the notion that infants, after their first year of life, interpret interactions of animate agents, and demonstrate preference for agents acting prosocially and/or aversion for agents acting antisocially. Noteworthy in our study, cartoons with human-like characters (rather than animal puppets or wooden blocks with glued eyes) were successfully used with 12- to 36-months-old infants, which suggested that this novel display was relevant to assess social evaluation, at least within this age range. Similar movies were also successfully used by Gredebäch et al. (2015) to investigate the neural correlates of prosocial preferences in young infants.

\section{References}

Fantz, R.L. (1961). The origin of form perception. Scientific American, 204, 66-72.

Gredebäck, G., Kaduk, K., Bakker, M., Gottwald, J., Ekberg, T., Elsner, C., Reid, V., \& Kenward, B. (2015). The neuropsychology of infants' pro-social preferences. Developmental Cognitive Neuroscience, 12, 106-113.

Hamlin, J. K. (2013). Moral Judgment and Action in Preverbal Infants and Toddlers: Evidence for an Innate Moral Core. Current Directions in Psychological Science, 22, $186-193$.

Hamlin, J. K. (2015). The case for social evaluation in preverbal infants : Gazing toward one ' s goal drives infants ' preferences for Helpers over Hinderers in the hill paradigm. Frontiers in Psychology, 5:1563, 1-9.

Hamlin, K. J., \& Wynn, K. (2011). Young infants prefer prosocial to antisocial others. Cognitive Development, 26, 30-39. 
Hamlin, K. J., Wynn, K., \& Bloom, P. (2007). Social evaluation by preverbal infants. Nature, $450,557-559$.

Hamlin, K. J., Wynn, K., \& Bloom, P. (2010). Three-month-olds show a negativity bias in their social evaluations. Developmental Science, 13, 923-929.

Kelly, D. J., Liu, S., Ge, L., Quinn, P. C., Slater, A. M., Lee, K., ... Pascalis, O. (2007). Cross-Race Preferences for Same-Race Faces Extend Beyond the African Versus Caucasian Contrast in 3-Month-Old Infants. Infancy, 11, 87-95.

Maxwell, L., \& Raftseder, E. (2015). Do toddlers have an innate moral core? An investigation into whether toddlers reward a good outcome over a good goal. Proceeding of BCCCD15, p. 143, Budapest CEU Conference on Cognitive Development.

Salvadori, E., Blasekova, T., Karap, Z., Mascaro, O., Tatone, D., Volein, A., \& Csibra, G. (2015). Probing the strength of infants' preference for helpers over hinderers: Two replication attempts of Hamlin \& Wynn, 2011. Proceeding of BCCCD15, p. 183, Budapest CEU Conference on Cognitive Development.

Scarf, D., Imuta, K., Colombo, M., \& Hayne, H. (2012). Social evaluation or simple association? Simple associations may explain moral reasoning in infants. PloS One, 7 , e42698. 


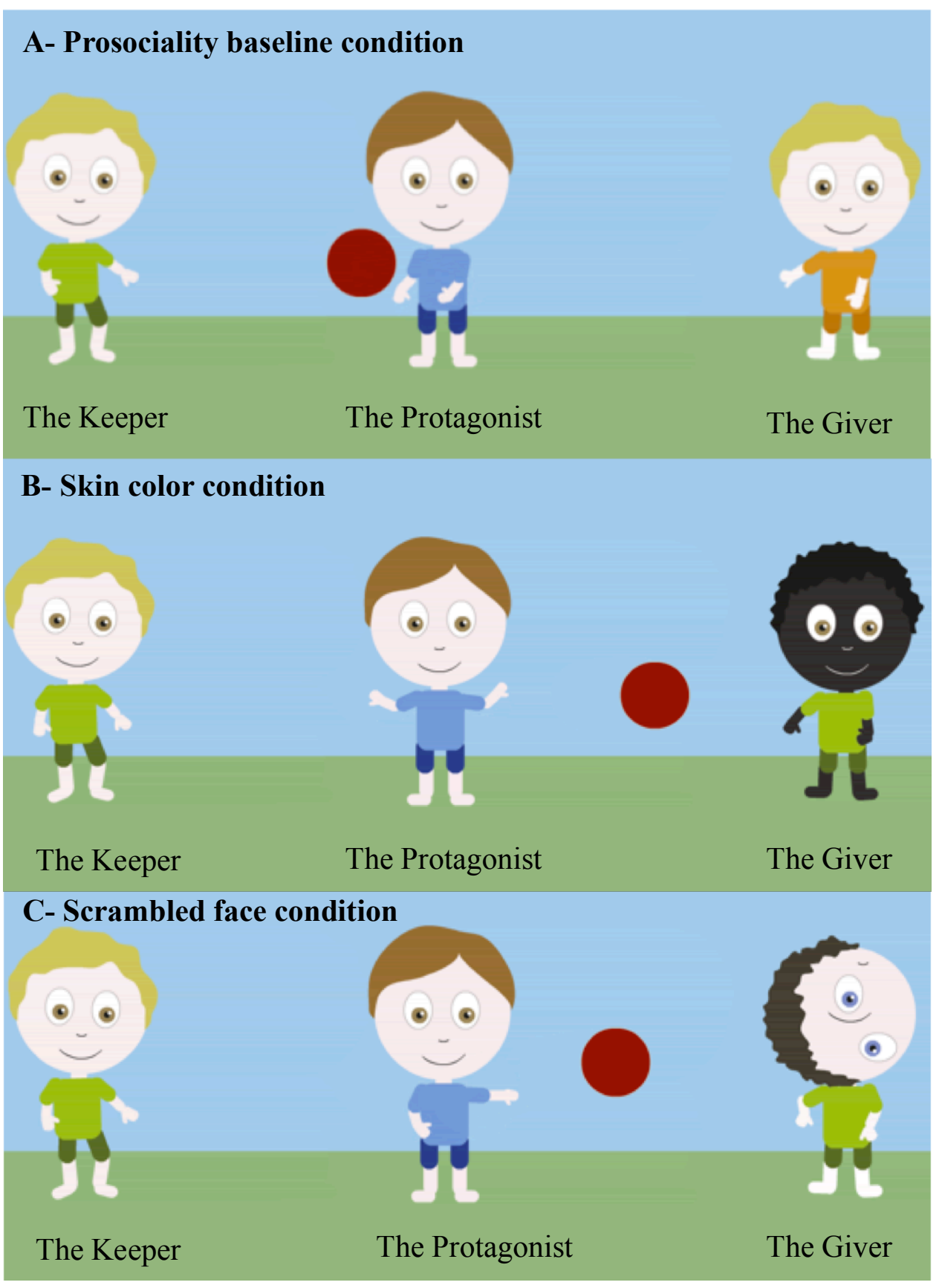

Fig. 1. Illustration of the display used in each experimental condition. A-Prosociality baseline condition: The Giver and the Keeper had white skin and normal facial features. B-Skin color condition: The Giver had dark skin, the Keeper had white skin, both had normal facial features. C-Scrambled face condition: The Giver had a scrambled face, the Keeper had a normal face, both had white skin. 


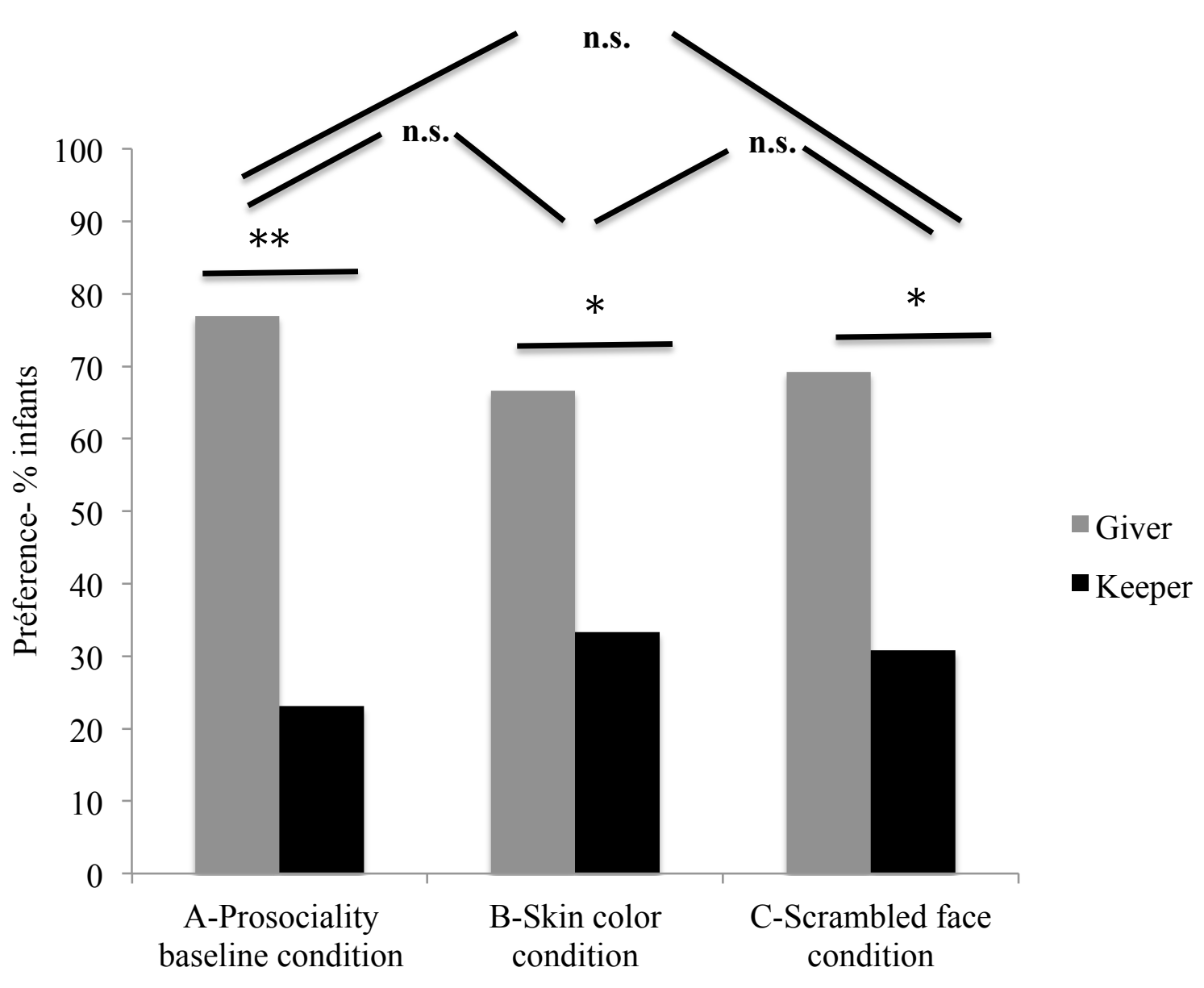

Fig. 2. Percent of infants who chose the Giver and the Keeper character in each experimental condition. n.s. non significant, $* p<.05, * * p<.01$ 